\title{
Repugnance Management and Transactions in the Body ${ }^{\dagger}$
}

\author{
By Kieran Healy and Kimberly D. Krawiec*
}

Alvin Roth remarks that, although it often gets in the way of market exchanges, "predicting when repugnance will play a decisive role is difficult, because apparently similar activities and transactions are often judged differently" (Roth 2007, p. 42-43). It certainly took the staff of Space World by surprise. In November of 2016, in the Japanese city of Kitakyushu, the management of the Space World theme park was looking for a way to boost attendance at their ice rink. To this end, they purchased about five thousand fish of various kinds from the local market-sprats, mackerel, rays, and other species-and froze them into the rink in a variety of attractive and whimsical patterns. The park's management thought that both the innovative display and the prospect of gliding above the suspended fish would surprise and delight visitors to the park all through the winter.

People were disgusted. Public reaction was swift, unequivocal, and rapidly international in scale. The rink was condemned as creepy, grotesque, and abusive; an insulting waste of food; and an affront to both human and piscine dignity. Space World's spokespeople scrambled to react. They apologized profusely. They lamented that they had perhaps not done a good enough job explaining to the public that the fish were already dead when they had been frozen in the rink. (Pointing this out did not seem to help matters.) By the end of the affair, the story was running around the world, the rink was being thawed, and Space World was reportedly considering holding a memorial service for the fish.

\footnotetext{
*Healy: Sociology Department, Duke University, 417 Chapel Drive, Durham, NC 27708 (e-mail: kjhealy@soc. duke.edu); Krawiec: Duke University School of Law, 210 Science Drive, Durham, NC 27708 (e-mail: krawiec@law. duke.edu) .

${ }^{\dagger}$ Go to https://doi.org/10.1257/aer.p20171108 to visit the article page for additional materials and author disclosure statement(s).
}

\section{Repugnance as a Constraint on Exchange}

How should we think about this or similar cases? It is tempting to begin, as the park management initially did, by enumerating the various ways that the public's reaction was irrational or inconsistent. An ice rink with thousands of artistically arranged dead fish turned out to be repugnant. But it is easy to think of very similar cases that probably would not have provoked the same reaction. A local market filled with the same dead fish destined for dinner plates is not repugnant. Neither would a tank full of thousands of trapped living fish provoke much reaction, most of the time. Moving along a different axis, visitors to natural history museums see pinned, stuffed, or otherwise preserved animals all the time. We could easily multiply examples. Once we see that the initial repugnant reaction has a weak basis, it should be possible to focus on the benefits-like a nice family day out at Space World-that would flow from allowing those who would like to visit the rink to buy a ticket.

From the 1980s into the 2000s, a steady stream of articles by economists pursued something like this strategy when analyzing the shortage of transplantable human organs, and especially kidneys (Cohen 1989; Hansmann 1989; Blair and Kaserman 1991; Kaserman and Barnett 2002). An exemplary treatment, by Becker and Elías (2007) estimates the likely price of transplantable kidneys and livers, and the probable increase in supply as the result of introducing monetary incentives. The authors also consider various criticisms and objections. They point out that many quite similar transactions do not provoke the reaction that exchange is immoral, or a suspect case of "commodification." They note the similarities to surrogacy, for instance, as one of several cases of exchange in human goods that goes ahead without much controversy. They also develop the example of voluntary paid military service as a useful point of comparison, involving as it does similar questions 
of bodily risk, quality control, the independent moral value of the activity, and the possibility of crowding out of other motives. And like most of the previous literature in this vein, they end by quite reasonably arguing that reliance on a purely altruistic system "imposes an intolerable burden on thousands of very ill individuals who suffer and sometimes die" as they await a transplant (Becker and Elías 2007, p. 22).

This way of framing the discussion within economics descends from a debate between Arrow (1972) and Singer (1973) in the wake of Titmuss's (1971) indictment of the market for blood in his book The Gift Relationship. Later interventions by Walzer (1983) and Anderson (1993) kept the engagement on mostly philosophical terrain, focused on the idea of commodification. Economists were generally unpersuaded by the idea, and instead emphasized the welfare benefits flowing from mutually beneficial exchanges, even when those exchanges might seem distasteful to some observers. Debate tended to stall out in disagreements about how to weigh gains from trade against moral goods.

Roth (2007) took a slightly different approach. His discussion of repugnance acknowledged both its often arbitrary quality and its stubborn persistence in the case of many (but not all) exchanges in bodily goods. The focus on repugnance as an empirical phenomenon, in contrast to commodification as a moral problem, opened a connection to research on the psychology and sociology of exchange. It also shifted attention to the role of repugnance in constraining trade, and the challenge it posed when considered as a problem of market design. The goal then became one of constructing systems - such as an in-kind kidney exchange scheme-that succeed in realizing gains without triggering a repugnance reaction among participants or among observers in the wider world.

\section{Repugnance as a Management Problem}

In the easiest transactions, prices specify the costs and gains for all those involved and there is no controversy about the goods or the exchange partners. While it is tempting to think of these as the simplest cases, often it is the quickest and most straightforward transactions that require the most institutional infrastructure. Stock exchange trades, to take just one example, happen easily thanks to a vast institutional and regulatory structure that underpins and guides them.

Other transactions are not so clear-cut. In such cases, both participants and observers want to establish what sort of exchange is happening, in order to ensure not just that it is mutually beneficial but also that it is in some sense legitimate, respectable, or appropriate to the statuses or roles of those involved. It is in these circumstances that repugnance can appear, and also when various strategies to ameliorate it may be deployed.

Social scientists have documented the strategies that people employ to manage these awkward exchanges. They are generally interpreted as cases where something in a socially sacred category threatens to come into contact with the generally profane world of money and prices (Bohannan 1955). The exchange may be shut down, actively reclassified, or reframed (Fiske and Tetlock 1997). It may take place after substantial "relational work" is done by participants to manage its potentially negative effects (Zelizer 2005). Or it may be structurally recast and obfuscated, so participants can plausibly claim it is not an exchange at all (Rossman 2014). The strategies are more stable than the particular sacred things, whichas Durkheim (1997) long ago argued—can be quite arbitrary.

The most widespread methods for ameliorating repugnance have deep roots. They often rely on some form of gift exchange, on a mutually understood local rule governing ongoing reciprocity between kinds of actors, or on contingent agreements concerning the acceptability of a transaction. Understanding basic strategies of reframing and obfuscation helps us see how exchanges are accomplished locally, and helps us understand how individuals reframe transactions to make them palatable.

However, the growth of potentially repugnant exchanges creates new problems. The scale and scope of trade in bodily goods, for example, means that individuals neither broker transactions on their own, nor individually agree on the character of individual exchanges. Instead, the management of repugnance happens organizationally and institutionally (Healy 2006). Organizational staff, e.g., in hospitals or procurement organizations, frame and manage the exchange for donors and recipients who are 
usually one-shot participants in a transplant process. This also means that organizations are embedded in ongoing relationships of their own, not with individual patients but with peer organizations and agencies involved in the process of supply and demand. Their staff will be concerned to establish the legitimacy of the organization as well as to defend its perceived interests (Healy and Krawiec 2012).

\section{Repugnance Management as a Legal Problem}

These strategies may give rise to legal problems that subsequently constrain the ability of market participants to engage in particular forms of repugnance management. In particular, the persistence of gift-like solutions to taboo trades may be at odds with a transaction's legal categorization as market-based, creating tension between an accepted, and useful, cultural narrative, on the one hand, and legal definitions and requirements, on the other.

Sometimes, the result of these tensions may be merely inconvenient, as when, for example, egg donors, having been told that the money received from egg donation is a thank-you gift, resist taxation of that same money as ordinary income, to the consternation of the IRS and tax courts. At other times, the result could be much more severe, as would be the case if innovations in kidney exchange were, ex post, ruled to violate the National Organ Transplantation Act's ban against valuable consideration, even though no money has changed hands. The egg donor example involves unpleasant tax consequences for individual donors and may-at least in the long term-undermine the gift narrative that market participants work so hard to foster. But the organ donation case could result in the termination of life-saving procedures and, in theory at least, the criminal prosecution of exchange participants and organizers.

At any particular layer, exchange partners or brokering organizations must manage the reactions of their peers. Coordinating organizations like hospitals, transplant centers, and fertility centers must work with both donors and recipients to find a format for the exchange that is both medically safe, acceptable in terms of costs and benefits, and not repugnant. Otherwise, participants will back out and the transaction will fail. But repugnance also arises vertically. State actors, like the IRS, the Department of Health and Human Services, and courts, are concerned about avoiding repugnant or corrupt transactions, too. As will be shown, decisions made at this level may rely on a quite different set of relevant facts or rules when it comes to determining whether an exchange violates a legal or ethical standard.

Egg donation-where the obfuscating role of gift exchange is particularly evident-provides a useful illustration of repugnance management's horizontal and vertical elements. Exchange in human eggs has long successfully incorporated substantial payments to donors. Although donors are well-compensated, fertility organizations, egg donors, and egg recipients all characterize egg donation as a precious gift. Payments to donors are often packaged as a "thank-you" gesture by recipients or as a form of cash compensation for discomfort experienced in the donation process that could never (and is not intended to) fully compensate a donor giving the miraculous "gift of parenthood." This framing is strongly encouraged by fertility organizations, who often remind donors not to think in self-interested terms about the money they will receive, and who distrust donors who seem overly motivated by the prospect of payment (Almeling 2011).

Although market participants may share a vision of egg donation as a gift-like exchange in which some money changes hands, this is not a categorization recognized by the law, which often requires firm definitions where participants would prefer none. In the case of egg donation, for example, some questions that arise are: Is the money received by donors taxable income? If not, then what do the payments represent? If donors are to be taxed, then what type of income is it: income from the sale of assets (the eggs) or income from the provision of a service?

Perhaps it is a testament to the power of gift framing that, until recently, there was no definitive statement on the proper tax treatment of proceeds earned from egg donation, despite the thousands of babies born each year in the United States from donated eggs. Instead, at least some egg donors simply contested the inclusion of their compensation in taxable income, with IRS acquiescence. The tax court intervened in 2015 , however. Although egg donation may be a loving and priceless gift in the eyes of exchange 
participants, from a tax perspective it is simply a risky job, like boxing, football, or fishing. ${ }^{1}$

The fact that egg donor compensation occurs within a gift-based cultural account poses other problems as well. Payments of up to $\$ 10,000$ are hard enough to square with a gift narrative, but participants managed it. Egg donation is physically risky, after all, and there was a general consensus that egg donors deserved something for their efforts. Besides, all market participants recognized that without some compensation there would be very few egg donors. But once incentives enter the picture they threaten to undermine gift framing entirely. Would fertility centers and patients compete for the most desirable egg donors? How do you square extremely large payments that vary with the donor's beauty, intelligence, or race with the notion that payments to egg donors are mere thank-you gestures or a token in recognition of physical discomfort?

To address these concerns, the fertility industry eventually settled on "ethical pricing guidelines" that limited egg donor compensation to a maximum of $\$ 10,000$ per donation cycle (Ethics Committee of the ASRM 2004). Such an agreement, they argued, would not only reinforce that egg donors were motivated, at least in part, by altruism, but would also protect against coercion and commodification, and ensure the safety of egg donation for both donors and recipients. Once again, however, the state (and the plaintiffs' bar) saw things differently. Specifically, they saw an illegal agreement among competitors not to compete on price, in violation of US antitrust law (Krawiec 2015). The resulting nationwide class action lawsuit eventually settled, with the fertility industry agreeing to remove the pricing guidelines and to implement no others in their place (Krawiec 2015).

\section{Conclusion}

Researchers have come a long way toward understanding the role of repugnance when considering transactions in the human body. Yet, often, the focus remains on exchange between individuals and how they mentally cope (or not) with repugnance. But these exchanges entail an

\footnotetext{
${ }^{1}$ Perez v. Commissioner of Internal Revenue, 144 T.C. 4 (2015).
}

additional "vertical" dimension. Organizational and state actors play a role both in directly managing repugnance in exchange and in placing limits on the specific repugnance management tools that market organizers may employ.

By treating repugnance as a problem that arises not only between individuals, but also at organizational and regulatory levels, we can better see why it is unlikely that a single, harmonized system of exchange in bodily goods will emerge with the passage of time. The consolidation and success of particular exchanges (such as with organs, eggs, or bone marrow) tends to create new problems in different parts of the system. The result is that the management of exchange in particular goods tends to fluctuate between different forms, depending on the kind of moral, ethical, or legal problem that people want to avoid.

\section{REFERENCES}

Almeling, Rene. 2011. Sex Cells. Oakland: University of California Press.

Anderson, Elizabeth. 1993. Value in Ethics and Economics. Cambridge, MA: Harvard University Press.

Arrow, Kenneth J. 1972. "Gifts and Exchanges." Philosophy and Public Affairs 1 (4): 343-62.

Becker, Gary S., and Julio Jorge Elías. 2007. "Introducing Incentives in the Market for Live and Cadaveric Organ Donations." Journal of Economic Perspectives 21 (3): 3-24.

Blair, Roger D., and David L. Kaserman. 1991. "The Economics and Ethics of Alternative Cadaveric Organ Procurement Policies." Yale Journal on Regulation 8 (2): 403-52.

Bohannan, Paul. 1955. "Some Principles of Exchange and Investment among the Tiv." American Anthropologist 57 (1): 60-70.

Cohen, Lloyd. 1989. "Increasing the Supply of Transplant Organs: The Virtues of a Futures Market." George Washington Law Review 58 (1): 1-51.

Durkheim, Emile. 1997. The Elementary Forms of Religious Life: A New Translation by Karen E. Fields. New York: Free Press.

Ethics Committee of the American Society for Reproductive Medicine. 2004. "Financial Incentives in Recruitment of Oocyte Donors." Fertility and Sterility 82 (1): 240-44.

Fiske, Alan Page, and Philip E. Tetlock. 1997. "Taboo Trade-offs: Reactions to Transactions 
That Transgress the Spheres of Justice." Political Psychology 18 (2): 255-97.

Hansmann, Henry. 1989. "The Economics and Ethics of Markets for Human Organs." Journal of Health Politics, Policy and Law 14 (1): $57-85$.

Healy, Kieran. 2006. Last Best Gifts: Altruism and the Market for Human Blood and Organs. Chicago: University of Chicago Press.

Healy, Kieran, and Kimberly D. Krawiec. 2012. "Custom, Contract, and Kidney Exchange." Duke Law Journal 62 (3): 645-70.

Kaserman, David, and A. H. Barnett. 2002. The U.S. Organ Procurement System: A Prescription for Reform. Washington, DC: American Enterprise Institute Press.

Krawiec, Kimberly D. 2015. "Markets, Morals, and Limits in the Exchange of Human Eggs."
Georgetown Journal of Law and Public Policy 13: 349-65.

Rossman, Gabriel. 2014. "Obfuscatory Relational Work and Disreputable Exchange." Sociological Theory 32 (1): 43-63.

Roth, Alvin E. 2007. "Repugnance as a Constraint on Markets." Journal of Economic Perspectives 21 (3): 37-58.

Singer, Peter. 1973. "Altruism and Commerce: A Defense of Titmuss Against Arrow." Philosophy and Public Affairs 2 (3): 312-20.

Titmuss, Richard M. 1971. The Gift Relationship: From Human Blood to Social Policy. New York: The New Press.

Walzer, Michael. 1983. Spheres of Justice. New York: Basic Books.

Zelizer, Viviana. 2005. The Purchase of Intimacy. Princeton: Princeton University Press. 